\title{
The Activation of Factor $X$ and Prothrombin by Recombinant Factor Vlla In Vivo Is Mediated by Tissue Factor
}

\author{
Hugo ten Cate, * Kenneth A. Bauer," \\ Bryon L. Kass," and Robert D. Rosenberg \\ *Department of Internal Medicine, Slotervaart Hospital, and ${ }^{\ddagger}$ Center for Hemostasis, Thrombosis, Atherosclerosis, and Inflammation \\ Research, Academic Medical Center, 1105 AZ Amsterdam, The Netherlands; $\$$ Department of Medicine, Beth Israel Hospital and \\ "Brockton-West Roxbury Department of Veterans Affairs Medical Center, Harvard Medical School, Boston, Massachusetts 02215; 'The \\ Scripps Research Institute, La Jolla, California 92037; ${ }^{* *} R$. W. Johnson Pharmaceutical Research Institute, San Diego, California \\ 92121; and ${ }^{\ddagger \pm}$ Department of Biology and Whitaker College, Massachusetts Institute of Technology, Cambridge, Massachusetts 02139
}

\begin{abstract}
The human coagulation system continuously generates very small quantities of Factor $\mathrm{Xa}$ and thrombin. Current evidence suggests that basal level activation of the hemostatic mechanism occurs via Factor VIIa-dependent activation of Factor $X$, but direct proof has not been available for the participation of tissue factor in this pathway. To examine this issue, we infused relatively high concentrations of recombinant Factor VIIa ( $\sim 50 \mu \mathrm{g} / \mathrm{kg}$ body wt) into normal chimpanzees and observed significant increases in the plasma levels of Factor IX activation peptide, Factor $\mathrm{X}$ activation peptide, and prothrombin activation fragment $F_{1+2}$. Metabolic turnover studies with radiolabeled Factor IX activation peptide, Factor $X$ activation peptide, and $F_{1+2}$ indicate that elevated levels of the activation peptides are due to accelerated conversion of the three coagulation system zymogens into serine proteases. The administration of a potent monoclonal antibody to tissue factor, which immediately neutralizes function of the Factor VIIa-tissue factor complex in vitro, abolishes the activation of Factor $\mathbf{X}$ and prothrombin mediated by the infused recombinant protein, and also suppresses basal level activation of Factor $I X$ and Factor $X$. The above results suggest that recombinant Factor VIIa functions as a prohemostatic agent by interacting with endogenous tissue factor sites, but definitive proof will require studies in hemophilic animals using relevant hemostatic endpoints. (J. Clin. Invest. 1993. 92:1207-1212.) Key words: blood coagulation • Factor VII • tissue factor • radioimmunoassay • monoclonal antibody
\end{abstract}

\section{Introduction}

The human coagulation mechanism is composed of intrinsic and extrinsic reaction cascades, which converge at the level of Factor $\mathrm{X}$ and lead through a final common pathway to the generation of thrombin and formation of fibrin $(1,2)$. Previous in vitro investigations demonstrated that intrinsic cascade function involves the Factor XIIa-dependent activation of Factor XI, and the subsequent Factor XIa-dependent activation of Factor IX. However it has recently been shown that thrombin can activate Factor XI in the presence of a negatively

Address correspondence to Kenneth A. Bauer, M.D., Beth Israel Hospital, 330 Brookline Avenue, Boston, MA 02215.

Received for publication 21 December 1992 and in revised form 9 April 1993.

The Journal of Clinical Investigation, Inc.

Volume 92, September 1993, 1207-1212 charged surface $(3,4)$. Early in vitro studies revealed that the Factor VIIa-tissue factor (TF) ${ }^{1}$ complex cannot only activate Factor X, but also Factor IX $(5,6)$. Using specific immunoassays for activation peptides, we have shown in humans that Factor VII, but not Factor XI, is mainly responsible for Factor IX activation under basal conditions (7). Indeed, Factor VIIdeficient patients exhibit drastically reduced plasma concentrations of Factor IX activation peptide (FIXP) and Factor X activation peptide (FXP), which are restored to normal levels by infusion of relatively low concentrations $(10-20 \mu \mathrm{g} / \mathrm{kg}$ body wt) of recombinant Factor VIIa (7-9).

Although Factor VIIa at physiological concentrations possesses very little ability to directly activate Factor $\mathrm{X}$ in vitro (10), there is currently no direct evidence that activation of this zymogen by Factor VIIa in vivo requires association with TF. Patients with Factor VIII inhibitors have been infused with large amounts of recombinant Factor VIIa with beneficial effects on hemostasis (11-13). Considerable doubt exists whether TF is required for the above response, and it has been demonstrated that a phospholipid surface alone is sufficient to promote activation of Factor X by Factor VIIa (14-16). In the present communication, we infuse relatively high concentrations of recombinant Factor VIIa into normal chimpanzees and demonstrate accelerated activation of Factor IX, Factor X, and prothrombin. The administration of a potent $\mathrm{mAb}$ directed against human TF to the animals inhibits the activation of Factor $\mathrm{X}$ and prothrombin by the infused recombinant protein, and also suppresses basal level activation of Factor IX and Factor X.

\section{Methods}

Chimpanzees. Adult male chimpanzees (Pan troglodytes) were housed at the New York University Medical Center Laboratory for Experimental Medicine and Surgery in Primates (Tuxedo, NY) and the New Mexico Regional Primate Research Laboratories (Alamagordo, NM). The animals selected for study weighed between 52 and $62 \mathrm{~kg}$, exhibited normal kidney as well as liver function, and had not participated in infectious disease investigations during the time period of the Factor VIIa infusions. The general anesthetics used in these investigations were either ketamine or halothane, and the length of the experiments did not exceed $6 \mathrm{~h}$. In separate control experiments, no significant differences were observed between the two anesthetics with regard to the levels of activation peptides generated (data not shown). The study

\footnotetext{
1. Abbreviations used in this paper: FIXP, Factor IX activation peptide; $F_{1+2}$, prothrombin activation fragment; FPA, fibrinopeptide; FXP, Factor $\mathrm{X}$ activation peptide; TF, tissue factor; TFPI, TF pathway inhibitor.
} 
protocols were approved by the animal health and welfare committee of the primate centers and were conducted according to the guidelines of the American Physiological Society.

Blood collection and processing. Venous blood was obtained from the antecubital veins of chimpanzees by two syringe technique using 21-gauge butterfly needles. Blood samples for the FIXP and FXP RIAs were drawn into plastic syringes preloaded with the following anticoagulant: $38 \mathrm{mmol} /$ liter citric acid, $75 \mathrm{mmol} /$ liter sodium citrate, 136 $\mathrm{mmol} /$ liter dextrose, $6 \mathrm{mmol} /$ liter EDTA, $6 \mathrm{mmol} /$ liter adenosine, and $25 \mathrm{U} / \mathrm{ml}$ heparin. The ratio of anticoagulant to blood used was 0.2:1.0 (vol/vol). For the $F_{1+2}$ and fibrinopeptide A (FPA) assays, an anticoagulant containing a thrombin inhibitor, EDTA, and aprotinin was purchased from Byk-Sangtec (Dietzenbach, Germany); the ratio of anticoagulant to blood used was 0.1:0.9 ( $\mathrm{vol} / \mathrm{vol})$. The measurements of coagulation factors, Factor VII/VIIa antigen levels, and cell counts were carried out on blood collected in sodium citrate at a final concentration of $3.8 \%(\mathrm{wt} / \mathrm{vol})$. All plasma specimens were centrifuged at $4^{\circ} \mathrm{C}$ for $20 \mathrm{~min}$ at $1,600 \mathrm{~g}$, and stored at $-70^{\circ} \mathrm{C}$ until assayed.

Assays. Factor VII/VIIa antigen levels were determined with an enzyme-linked immunosorbent assay (Asserachrom VII; American Bioproducts Co., Parsippany, NJ). The FIXPs, FXPs, and were quantified with specific immunoassays as described previously $(7,8,17$, 18). The FPA measurements were established by radioimmunoassay with a kit provided by Byk-Sangtec.

Chimpanzee protein purification. Chimpanzee Factor IX, Factor X, and prothrombin were isolated from barium chloride-adsorbed plasma by affinity chromatography using specific mAbs for human plasma proteins, which were generously provided by Drs. D. Bing (Center for Blood Research, Boston, MA), D.S. Fair (University of Texas, Tyler, TX), and B. Furie (New England Medical Center, Boston, MA), respectively. Briefly, chimpanzee plasma (1 liter) was subjected to barium chloride adsorption (final concentration $70 \mathrm{mmol} /$ liter), elution with $0.17 \mathrm{~mol} /$ liter trisodium citrate, and dialysis against a Tris-buffered saline solution $(0.05 \mathrm{M}$ Tris- $\mathrm{HCl}, 0.5 \mathrm{M} \mathrm{NaCl}$, pH 7.4) containing $0.02 \%$ ( vol/vol) Tween 20 (19). The anti-human Factor IX mAb matrix (6.6 mg of magnesium-dependent antibody coupled to $2 \mathrm{ml}$ of Sepharose [Pharmacia Fine Chemicals, Piscataway, $\mathrm{NJ}$ ) was equilibrated with dialysis buffer adjusted to $7.5 \mathrm{mmol} / \mathrm{liter}$ $\mathrm{MgCl}_{2}$. The plasma eluate was circulated through the affinity column for $90 \mathrm{~min}$, the matrix was washed with 1 liter of equilibration buffer, and Factor IX was eluted with the same buffer to which was added 10 mmol/liter EDTA, but no $\mathrm{MgCl}_{2}$. The purification of Factor $\mathrm{X}$ was accomplished in a similar manner to that described for Factor IX, except that adsorption of plasma eluate to the anti-human Factor $\mathrm{X}$ $\mathrm{mAb}$ ( $5 \mathrm{mg}$ of antibody coupled to $5 \mathrm{ml}$ of Agarose [Pharmacia Fine Chemicals]) was carried out with TBS containing $5 \mathrm{mmol} /$ liter $\mathrm{CaCl}_{2}$, and bound protein was eluted with Tris-buffered saline containing 20 mmol/liter of EDTA. The isolation of prothrombin was undertaken as outlined above except that adsorption of plasma eluate to the anti-human prothrombin mAb (6 mg of antibody coupled to $2 \mathrm{ml}$ of Sepharose) was conducted with TBS containing $10 \mathrm{mmol} / \mathrm{liter} \mathrm{CaCl}_{2}$ and bound protein was eluted with TBS containing $3 \mathrm{mmol} /$ liter EDTA.

The final concentrations of the chimpanzee Factor IX, Factor X, and prothrombin preparations were $100 \mathrm{nmol} /$ liter, and $617 \mathrm{nmol} /$ liter, and 1,473 $\mathrm{nmol} /$ liter, respectively, as determined by immunoassays directed against the various human proteins $(7,18)$. The above products were also examined by nondenaturing gel electrophoresis, and were shown to be homogeneous with respect to size by the SDS gel electrophoretic system of Laemmli (20). The individual vitamin Kdependent proteins purified from chimpanzee plasma migrated at the same rate as human Factor IX, human Factor X, and prothrombin, respectively. The levels of contaminating activation peptides in the Factor IX, Factor X, and prothrombin preparations as judged by immunoassays against the human activation fragment counterparts were undetectable, $1 \%$, and $0.1 \%$, respectively, on a molar basis as compared to the zymogens. Human Factor IX, human Factor X, and prothrombin were obtained from Enzyme Research Laboratories, South Bend, IN, and were physically homogeneous as judged by nondenaturating gel electrophoresis. The human coagulation proteins were diluted in
$0.05 \mathrm{M}$ Tris- $\mathrm{HCl}, 0.10 \mathrm{M} \mathrm{NaCl}$, $\mathrm{pH} 7.5$, containing $4 \%$ (wt/vol) ovalbumin to concentrations comparable to the chimpanzee preparations. The chimpanzee and human proteins were then activated in vitro, and the levels of activation peptides determined. The Factor IX and Factor $\mathrm{X}$ preparations were incubated for $3 \mathrm{~h}$ at $37^{\circ} \mathrm{C}$ with final concentrations of $5.7 \mathrm{nmol} /$ liter to $50 \mathrm{nnmol} /$ liter recombinant Factor VIIa, 4.9 nmol/liter relipidated human brain tissue factor (Drs. Ronald Bach and Yale Nemerson, Mount Sinai Medical Center, New York), and $4.9 \mathrm{mmol} /$ liter $\mathrm{CaCl}_{2}$. Similarly, prothrombin preparations were incubated for $60 \mathrm{~min}$ at $24^{\circ} \mathrm{C}$ in $1 \mathrm{ml}$ reaction mixtures containing $10 \mathrm{mM}$ $\mathrm{CaCl}_{2}$ with $10 \mu \mathrm{g}$ human Factor $\mathrm{V}, 10 \mu \mathrm{g}$ human Factor $\mathrm{Xa}, 500 \mu \mathrm{g}$ prothrombin, and $70 \mu \mathrm{g}$ rabbit cephalin.

Determination of the metabolic behavior of activation peptides. The radiolabeling of FIXP, FXP, and $\mathrm{F}_{1+2}$ was carried out by the chloramine-T method of Greenwood et al. (21) using $3 \mu \mathrm{g}$ of human activation peptide and $0.5 \mathrm{mCi}$ of carrier-free $\mathrm{Na}^{125} \mathrm{I}$ or $\mathrm{Na}^{131} \mathrm{I}$ ( New England Nuclear, Billerica, MA). The activation fragments were separated from free iodide by Sephadex G-10 gel filtration (FIXP and FXP), or Sephadex G-25 gel filtration $\left(F_{1+2}\right)$ (Pharmacia Fine Chemicals). Before administration of radiolabeled peptide, animals were given $1 \mathrm{ml}$ of $\mathrm{Lu}$ gol's solution in their drinking water, and the above treatment was continued for three days after infusion. Approximately $50 \mu \mathrm{Ci}$ of labeled peptide was infused as a bolus into a peripheral vein of chimpanzees, and serial blood samples were drawn by two-syringe technique into the anticoagulant used for the $F_{1+2}$ and FPA assays through an indwelling venous catheter placed in the opposite arm vein. After centrifuging the blood samples at $1,600 \mathrm{~g}$ for $10 \mathrm{~min}$, the ${ }^{125} \mathrm{I} /{ }^{131} \mathrm{I}$ counts in $0.5 \mathrm{ml}$ of plasma were quantified in a Gamma 8000 Counting System (Beckman Instruments Inc., Irvine, CA). The plasma protein radioactivity determinations are described as a function of time by a two-exponential curve, $\mathrm{C}_{1} \mathrm{e}^{-\mathrm{rlt}}+\mathrm{C}_{2} \mathrm{e}^{-\mathrm{r} 2 \mathrm{t}}(22)$. The fractional breakdown rate, $k_{\mathrm{B}}$, was calculated from $\left(\mathrm{C}_{1} / \mathrm{r}_{1}+\mathrm{C}_{2} / \mathrm{r}_{2}\right)^{-1}(22)$.

Recombinant proteins and monoclonal antibodies. Human recombinant Factor VIIa (23) was obtained as a lyophilized powder from Novo Nordisk (Gentofte, Denmark) and was reconstituted in sterile water before use. The anti-TF mAb TF8-5G9, which blocks Factor X activation by the Factor VIIa-TF complex in vitro, was provided at a protein concentration of $5.5 \mathrm{mg} / \mathrm{ml}$ in $\operatorname{PBS}(24,25)$.

Statistical analysis. The within and between group differences were analyzed by ANOVA, and $P$ values were calculated with NewmanKeul's test to correct for multiple comparisons (26). $P$ values below 0.05 were considered statistically significant.

\section{Results}

The immunoreactivities of chimpanzee FIXP, chimpanzee FXP, and chimpanzee $F_{1+2}$ were compared with their respective human fragment homologues. This was accomplished by activating purified chimpanzee and human zymogens, which had been quantified by immunoassays using human proteins, and then measuring the levels of activation peptides using immunoassays directed against the human activation fragments. On a molar basis, the results obtained show that chimpanzee Factor IX, chimpanzee Factor X, and chimpanzee prothrombin were converted to their activated products at a level of 100 , 61 , and $100 \%$, respectively, whereas human Factor IX, human Factor $\mathrm{X}$, and human factor prothrombin were converted to their activated products at a level of 87,75 , and $91 \%$, respectively, under identical reaction conditions. These data indicate that the immunoreactivities of chimpanzee and human zymogens and the respective activation peptides are virtually identical.

Given these observations, we used immunoassays previously developed to quantify human coagulation zymogen activation to measure the effects of recombinant human Factor VIIa on the hemostatic mechanism of chimpanzees. The intravenous administration of $3 \mathrm{mg}$ of human recombinant Factor 
Table I. Temporal Changes in Plasma FIXP Levels after Infusion of Recombinant Factor VIIa (3 mg) Alone, or in Combination with $\mathrm{mAb}$ TF8-5G9 (600 $\mu \mathrm{g} / \mathrm{kg}$ Body Wt) in Chimpanzees

\begin{tabular}{|c|c|c|c|c|c|c|c|c|c|}
\hline \multirow[b]{2}{*}{ Animal } & \multicolumn{9}{|c|}{$\min$} \\
\hline & $t=0$ & $t=5$ & $t=15$ & $t=30$ & $t=60$ & $t=120$ & $t=180$ & $t=240$ & $t=300$ \\
\hline \multicolumn{10}{|c|}{ pmol/liter } \\
\hline \multicolumn{10}{|c|}{ Factor VIIa } \\
\hline 1 & 103 & 160 & 199 & 167 & 161 & 132 & 154 & 101 & 109 \\
\hline 2 & 165 & 151 & 222 & 192 & 224 & 179 & 132 & 121 & 143 \\
\hline 3 & 116 & 111 & 137 & 141 & 179 & 162 & 118 & 116 & 122 \\
\hline 4 & 123 & 207 & ND & 223 & 180 & 166 & 126 & 134 & 116 \\
\hline 5 & 196 & 199 & 280 & 393 & 345 & 294 & 252 & 203 & 197 \\
\hline Mean & 141 & 166 & $210^{*}$ & $223 \ddagger$ & $218 \S$ & 187 & 156 & 135 & 137 \\
\hline SEM & 17 & 17 & 30 & 44 & 33 & 28 & 25 & 18 & 16 \\
\hline \multicolumn{10}{|c|}{ Factor VIIa + TF8-5G9 } \\
\hline 6 & 234 & ND & ND & 227 & 259 & 237 & 188 & 143 & 120 \\
\hline 7 & 153 & 178 & 230 & 292 & 305 & 296 & 230 & 209 & 168 \\
\hline 8 & 280 & 364 & 375 & 499 & 470 & 409 & 314 & 337 & 260 \\
\hline Mean & 222 & 271 & 302 & $339^{\|}$ & $345^{\|}$ & 314 & 244 & 230 & 183 \\
\hline SEM & 37 & 93 & 72 & 82 & 64 & 50 & 37 & 57 & 41 \\
\hline
\end{tabular}

${ }^{*} P<0.05,{ }^{\ddagger} P<0.01,{ }^{\S} P<0.02$, as compared with FIXP at $t=0$. " $0.05<P<0.10$ as compared with FIXP at $t=0$.

VIIa ( $\sim 50 \mu \mathrm{g} / \mathrm{kg}$ body $\mathrm{wt}$ ) to five chimpanzees produced at 5 min an immediate increase in mean Factor VII/VIIa antigen levels from $53 \%$ of normal \pm 6.4 (SD) to $191 \% \pm 21$. The levels only gradually returned towards baseline levels, and remained elevated at $88 \% \pm 9.0(\mathrm{SD})$ at $5 \mathrm{~h}$. The augmentation of the plasma Factor VIIa measurements was associated with an average increase in FIXP and FXP of 1.6-fold at 30 min (Table I) and 3-fold at 15 min (Table II), respectively. These elevations gradually returned to baseline values at $4 \mathrm{~h}$. The elevation in plasma Factor VIIa concentrations also was associated with an increase in mean $\mathrm{F}_{1+2}$ levels of 2.2 -fold at $2 \mathrm{~h}$, which remained high at the termination of the experiments (Table III). The time-dependent changes in plasma FPA levels were virtually identical to those of $F_{1+2}$, rising from $8.8 \mathrm{nmol} /$ liter to a peak of $68.2 \mathrm{nmol} /$ liter at $1 \mathrm{~h}$, and remained elevated at $20.8 \mathrm{nmol} /$ liter at the end of the experiments (data not shown). It should be noted that the highest concentrations of $\mathrm{F}_{1+2}$ as well as FPA in chimpanzees were observed at $1-2 \mathrm{~h}$, which were delayed as

Table II. Temporal Changes in Plasma FXP Levels after Infusion of Recombinant Factor VIIa (3 mg) Alone, or in Combination with $\mathrm{mAb} T F 8-5 \mathrm{G} 9(600 \mu \mathrm{g} / \mathrm{kg})$ in Chimpanzees

\begin{tabular}{|c|c|c|c|c|c|c|c|c|c|}
\hline \multirow[b]{2}{*}{ Animal } & \multicolumn{9}{|c|}{$\min$} \\
\hline & $t=0$ & $t=5$ & $t=15$ & $t=30$ & $t=60$ & $t=120$ & $t=180$ & $t=240$ & $t=300$ \\
\hline \multicolumn{10}{|c|}{ pmol/liter } \\
\hline \multicolumn{10}{|c|}{ Factor VIIa } \\
\hline 1 & 73 & 211 & ND & 184 & 124 & 93 & 64 & 38 & 31 \\
\hline 2 & 157 & 207 & 383 & 365 & 336 & 268 & 203 & 142 & 157 \\
\hline 3 & 108 & 214 & 317 & 316 & 328 & 174 & 162 & 116 & 113 \\
\hline 4 & 82 & 244 & ND & 329 & 214 & 116 & 93 & 86 & 93 \\
\hline 5 & 178 & 220 & 366 & 371 & 372 & 279 & 236 & 206 & 201 \\
\hline Mean & 120 & $219^{*}$ & $355^{\ddagger}$ & $313^{\ddagger}$ & $275^{\ddagger}$ & $186^{\S}$ & 152 & 118 & 119 \\
\hline SEM & 21 & 7 & 20 & 34 & 46 & 38 & 32 & 28 & 29 \\
\hline \multicolumn{10}{|c|}{ Factor VIIa + TF8-5G9 } \\
\hline 6 & 177 & ND & ND & 162 & 178 & 138 & 121 & 109 & 114 \\
\hline 7 & 72 & 83 & 97 & 110 & 94 & 95 & 65 & 60 & 50 \\
\hline 8 & 108 & 88 & 92 & 142 & 121 & 129 & 92 & ND & 77 \\
\hline Mean & 119 & 85.5 & 94.5 & 138 & 131 & 121 & 92.7 & 84.5 & 80.3 \\
\hline SEM & 31 & 2.5 & 2.5 & 15 & 25 & 13 & 16 & 24 & 18 \\
\hline
\end{tabular}

${ }^{*} P<0.002 .{ }^{\ddagger} P<0.001,{ }^{\S} P<0.05$, as compared with FXP at $t=0$. 
Table III. Temporal Changes in Plasma $F_{1+2}$ Levels after Intravenous Infusion of Recombinant Factor VIIa (3 mg) Alone, or in Combination with $\mathrm{mAb}$ TF8-5G9 $(600 \mu \mathrm{g} / \mathrm{kg}$ Body Wt) in Chimpanzees

\begin{tabular}{|c|c|c|c|c|c|c|c|c|c|}
\hline \multirow[b]{2}{*}{ Animal } & \multicolumn{9}{|c|}{$\min$} \\
\hline & $t=0$ & $t=5$ & $t=15$ & $t=30$ & $t=60$ & $t=120$ & $t=180$ & $t=240$ & $t=300$ \\
\hline \multicolumn{10}{|c|}{ pmol/liter } \\
\hline \multicolumn{10}{|c|}{ Factor VIIa } \\
\hline 1 & 1.01 & 0.99 & 1.16 & 1.32 & 1.68 & 1.31 & 1.43 & 1.41 & 1.46 \\
\hline 2 & 1.55 & 1.71 & 2.03 & 2.04 & 2.40 & 2.71 & 2.93 & 3.27 & ND \\
\hline 3 & 0.83 & 0.89 & 1.10 & 1.42 & 2.70 & 2.76 & 1.98 & 1.77 & 2.14 \\
\hline 4 & 1.23 & 0.96 & ND & 1.18 & 1.98 & 1.50 & 1.06 & 1.04 & 1.01 \\
\hline 5 & 0.68 & 1.59 & 1.80 & 2.18 & 2.59 & 3.34 & 3.89 & 3.03 & 2.72 \\
\hline Mean & 1.06 & 1.23 & 1.52 & 1.63 & $2.27^{*}$ & $2.32^{\ddagger}$ & $2.26^{\ddagger}$ & $2.10^{8}$ & 1.83 \\
\hline SEM & 0.15 & 0.17 & 0.23 & 0.20 & 0.19 & 0.39 & 0.51 & 0.44 & 0.38 \\
\hline \multicolumn{10}{|c|}{ Factor VIIa + TF8-5G9 } \\
\hline 6 & 0.79 & ND & ND & 0.74 & 0.78 & 0.81 & 0.80 & 0.76 & 0.72 \\
\hline 7 & 0.87 & 0.82 & 0.78 & 0.83 & 0.78 & 0.71 & 0.59 & 0.54 & 0.58 \\
\hline 8 & 1.53 & 1.42 & 1.63 & 1.55 & 1.56 & 1.71 & 1.52 & 1.21 & 1.09 \\
\hline Mean & 1.06 & 1.12 & 1.20 & 1.04 & 1.04 & 1.08 & 0.97 & 0.84 & 0.80 \\
\hline SEM & 0.23 & 0.30 & 0.42 & 0.26 & 0.26 & 0.32 & 0.28 & 0.20 & 0.15 \\
\hline
\end{tabular}

${ }^{*} P<0.02 .{ }^{\ddagger} P<0.01,{ }^{\&} P<0.05$, as compared with $\mathrm{F}_{1+2}$ at $t=0$.

compared with the peak FXP levels at $15-30 \mathrm{~min}$ and remained elevated for a greater period of time ( Tables II and III).

The elevated plasma concentrations of FIXP, FXP, and $F_{1+2}$ are attributable to increased zymogen activation and fragment generation rather than decreased clearance of the activation peptides. Either ${ }^{131} \mathrm{I}$-FIXP and ${ }^{125} \mathrm{I}-\mathrm{FXP}$ or ${ }^{125} \mathrm{I}-\mathrm{F}_{1+2}$ were infused into chimpanzees, with and without recombinant Factor VIIa; the fractional breakdown constants of the markers were estimated as outlined in Methods. The calculated fractional breakdown constants of FIXP, FXP, and $\mathrm{F}_{1+2}$ are 2.34, 2.59 , and 0.34 , respectively, in the absence of Factor VIIa, and $2.78,3.13$, and 0.43 , respectively, in the presence of the serine protease.

We then determined the involvement of TF in Factor VIIainduced alterations of coagulation system activation by administering to three chimpanzees a single intravenous dose of 600 $\mu \mathrm{g} / \mathrm{kg}$ of mAb TF8-5G9 just before infusing $3 \mathrm{mg}$ of recombinant enzyme. The elevations of the plasma concentrations of FXP and $\mathrm{F}_{1+2}$ induced by Factor VIIa were abolished ( Tables II and III), but suppression of the augmented FIXP levels was not observed in two of the three animals (Table I). We also examined the effect of the anti-TF mAb on the basal activity of the coagulation system. Two chimpanzees were administered $\mathrm{mAb}$ TF8-5G9 at a dose of $4 \mathrm{mg} / \mathrm{kg}$ body wt and two chimpanzees were infused with buffer without $\mathrm{mAb}$. The plasma levels of FIXP, FXP, and $F_{1+2}$ were determined initially and at varying intervals up to $24 \mathrm{~h}$ after mAb administration. The mean concentrations of FIXP and FXP decreased from 86.8 and 108 $\mathrm{pmol} /$ liter initially, to 41.9 and $66.4 \mathrm{pmol} /$ liter at $6 \mathrm{~h}$, and to 22.7 and $26.5 \mathrm{pmol} /$ liter at $24 \mathrm{~h}$, respectively, in the mAbtreated animals. In the control animals receiving buffer, the mean concentrations of FIXP and FXP were 202 and 158 $\mathrm{pmol} /$ liter initially, 200 and $177 \mathrm{pmol} /$ liter at $6 \mathrm{~h}$, and 170 and $121 \mathrm{pmol} /$ liter at $24 \mathrm{~h}$, respectively. These results suggest that neutralization of Factor VIIa-TF by the mAb suppresses basal level activation of Factor IX and Factor X, although a prolonged period of time is required for maximal effect. Interest- ingly, no downward trend was noted in plasma $F_{1+2}$ measurements (data not shown).

\section{Discussion}

Under physiologic conditions, the human coagulation system continuously generates small amounts of Factor $\mathrm{Xa}$ and thrombin $(8,18)$. The current evidence suggests that this basal level activation of the hemostatic mechanism occurs via Factor VIIa, and the participation of TF, though implied, remains to be substantiated (7-9). The present set of studies in chimpanzees attempts to resolve this issue. Firstly, we demonstrate that recombinant Factor VIIa infusions $(\sim 50 \mu \mathrm{g} / \mathrm{kg}$ body wt $)$ produce significant increases in the levels of FIXP, FXP, and $\mathrm{F}_{1+2}$. Secondly, we provide evidence that recombinant Factor VIIainduced elevations in the levels of FXP and $F_{1+2}$ are due to accelerated conversion of the coagulation system zymogens into their respective serine proteases rather than altered metabolic behavior of the activation fragments. Thirdly, we show that neutralization of TF and Factor VIIa-TF complex by administration of a specific mAb ( TF8-5G9) abolishes the activation of Factor $\mathrm{X}$ and prothrombin by recombinant Factor VIIa. Fourthly, we demonstrate that infusions of this anti-TF $\mathrm{mAb}$ lead to a time-dependent reduction in the basal levels of FIXP and FXP.

The experimental results outlined above can be explained by hypothesizing that TF molecules on cell surfaces in chimpanzees are saturated with varying proportions of Factor VII or Factor VIIa. The Factor VIIa-TF complex results from the proteolytic activation of Factor VII-TF by Factor Xa (27), Factor IXa (28), or Factor VIIa-TF (29). The resultant complexes initiate low level conversion of Factor IX and Factor $\mathrm{X}$ to active enzymes, the latter of which is responsible for a major portion of the basal activity of the coagulation mechanism (9). Upon infusion of recombinant Factor VIIa, increased amounts of Factor VIIa vis a vis Factor VII associate with TF. Given that the Factor VIIa-TF complex, as compared with Factor VII-TF interaction product, exhibits 120 -fold or greater procoagulant 
potency, the activation of Factor IX and Factor $\mathrm{X}$ is augmented $(30,31)$.

The FIXP and FXP levels in chimpanzees reach apogees at 15-30 min, somewhat delayed in comparison to the almost immediate increases in plasma concentrations of recombinant Factor VIIa. It is of interest to note that similar investigations conducted with lower doses of recombinant Factor VIIa (10$20 \mu \mathrm{g} / \mathrm{kg}$ body wt) in a severely Factor VII-deficient human with essentially no coagulant protein showed that production of FIXP and FXP takes place almost immediately, whereas virtually identical studies carried out with a Factor VII-deficient patient with a reasonable level of immunoreactive protein (17\% of normal) revealed that generation of FIXP and FXP occurs with some time delay as described above (9). Thus, it appears that plasma Factor VII must be competitively displaced from some TF sites by recombinant Factor VIIa before activation of Factor IX and Factor X is observed. The elevations of FXP and FIXP levels in chimpanzees persist for $\sim 2 \mathrm{~h}$, which cannot be explained by Factor VIIa-induced alterations in the metabolic behavior of the activation markers. Indeed, in the Factor VII-deficient patients who were infused with the recombinant protein, increased FXP and FIXP concentrations similarly occur over relatively prolonged periods of time (9). These persistent elevations probably result from ongoing activation of the zymogens by Factor VIIa-TF complex which is only slowly neutralized by tissue factor pathway inhibitor (TFPI) (32). The ambient plasma concentrations of TFPI average $2.5 \mathrm{nmol} /$ liter (33), which are about one fourth of the peak plasma levels of recombinant factor VIIa achieved in our chimpanzee studies. Thus, normal plasma concentrations of TFPI may be insufficient to inhibit the levels of Factor VIIaTF complex generated in our investigations. Alternatively, the requirement for TFPI to initially interact with Factor Xa followed by assembly with Factor VIla-TF may diminish the rate of inhibition to permit the observed FIXP and FXP activation rates (34). The elevations of $F_{1+2}$ as well as FPA in chimpanzees reach maximal values at $1-2 \mathrm{~h}$, which are delayed as compared to the peak levels of FXP at 15-30 min and remain raised for a longer period of time. The delayed generation of $F_{1+2}$ versus FXP and FIXP has also been observed in humans infused with recombinant Factor VIIa (9), and again cannot result from altered metabolic behavior of this activation marker in the animals. We hypothesize that the above phenomena may be due to a gradual time-dependent loss of TFPI inhibitory action or a time dependent activation of cell surfaces such as platelets resulting in enhanced prothrombinase assembly and function (35).

In two of the three chimpanzees that received anti-TF mAb before recombinant Factor VIIa, suppression of the increased FIXP levels was not observed, but increased Factor Xa generation as well as prothrombin activation did not occur. It has recently been demonstrated that an antibody to TF (TF811D12), which is undoubtedly identical to TF8-5G9, also inhibits Factor IX activation and Factor VII autoactivation in addition to Factor $\mathrm{X}$ activation by the Factor VIIa-TF complex in vitro (36). These antibodies do not interfere with Factor VIIa binding to TF, but rather appear to block the access of the macomolecular substrates to the enzyme's active site by steric hindrance $(25,36)$. We are uncertain of the reason for the discordance between the FIXP and FXP results in these animals. It could be due to the presence of an intermediate in the Factor IX activation pathway, such as Factor IX $\alpha$, that is resistant to inhibition by the anti-TF mAb upon conversion to
Factor IXa by Factor VIIa-TF (37). Alternatively, it is conceivable that TF exists in a different conformation in vivo as compared to in vitro and the $\mathrm{mAb}$ is unable to suppress Factor VIIa-TF-dependent conversion of Factor IX because of the altered structure.

In the studies in which anti-TF mAb was administered alone, a marked decrease was noted in the basal levels of FIXP and FXP, which was maximal at $24 \mathrm{~h}$. At present, we cannot explain the absence of a concordant decline in $\mathrm{F}_{1+2}$ concentrations. However, in Factor VII-deficient patients, our recombinant Factor VIIa studies indicate that the $F_{1+2}$ level is not as sensitive as FIXP and FXP to alterations in Factor VIIa-TF activity. In these patients, infusion of the recombinant Factor VIIa only induced two- to fourfold increases in $\mathrm{F}_{1+2}$ levels while the other two activation markers increased 10-20-fold.

Recombinant Factor VIIa preparations are currently being evaluated for treating bleeding episodes in hemophiliac patients with circulating Factor VIII inhibitors $(12,13)$. The above investigations demonstrate that the procoagulant effect of the recombinant protein requires interaction of enzyme with endogenous TF and that modest but prolonged bursts of coagulation system activity occur after infusion. These observations suggest that recombinant Factor VIIa preparations should be cautiously used in situations where high levels of TF expression are suspected to avoid excessive activation of the hemostatic mechanism that could lead to thrombotic complications.

The cellular site at which Factor VIIa interacts with TF has not been determined. The infused recombinant Factor VIIa could have complexed with endothelial cell TF. However, histochemical and in situ hybridization studies of human blood vessels fail to detect TF protein or TF mRNA in unperturbed endothelial cells, although TF protein has been observed on foam cells of atherosclerotic plaques $(38,39)$. It is possible that TF is constituitively or episodically expressed by endothelial cells and monocytes in quantities sufficient to maintain basal level coagulation activity, but too low to be readily detected. It seems unlikely that the occurrence of atherosclerotic plaques in chimpanzees could be responsible for basal activity of the coagulation mechanism since such lesions are infrequent in animals used in our studies that receive vegetarian diets (40). The infused recombinant Factor VIIa cannot readily be implicated in triggering synthesis of endothelial cell or monocyte TF. From in vitro studies, it is known that endotoxin as well as tumor necrosis factor stimulates biosynthesis of $\operatorname{TF}(41,42)$, but this is unlikely with recombinant Factor VIIa that is free of these mediators. The infused recombinant Factor VIIa could have reached subendothelial sites which has been documented with other large molecules under in vivo conditions (43). Perivascular and intramural fibroblasts express TF (39) and extremely small quantities can be functionally identified on vascular subendothelium (44).

In summary, we have demonstrated that the procoagulant response elicited by infusion of high dose recombinant Factor VIIa is dependent upon TF. The data suggest that the prohemostatic effect of the recombinant protein, observed in patients with Factor VIII inhibitors, necessitates the same interaction. However, our experiments were performed in chimpanzees, without a bleeding diathesis, that were not subjected to vascular trauma. At such sites, there could be excessive exposure of activated phospholipid membranes as well as TF. Thus definitive proof of the mechanism of action of recombinant Factor VIIa will require comparisons of relevant hemostatic endpoints in hemophilic animals receiving treatment in the 
presence and absence of $\mathrm{TF}$ inhibition. The present data also indicate that basal level coagulation system activity is at least partially dependent upon the amounts of TF on biologic surfaces in contact with blood components. We have previously documented age dependent elevations in activation peptide markers, and speculate that this type of biochemical hypercoagulability could, in part, be due to increased biosynthesis of TF in vivo (45).

\section{Acknowledgments}

We are grateful to Dr. W. W. Socha and the technical staff of Laboratory for Experimental Medicine and Surgery in Primates of New York University (Tuxedo, NY) for help with the chimpanzee experiments. We thank Drs. Ulla Hedner and Steven Glazer (Novo Nordisk, Gentofte, Denmark) for providing the recombinant Factor VIIa used in our investigations.

These studies were supported by National Institutes of Health grant PO1 HL-33014, and by a grant from the Dutch Organization for Scientific Research to Dr. ten Cate. Dr. Bauer is an Established Investigator of the American Heart Association.

\section{References}

1. MacFarlane, R. G. 1964. An enzyme cascade in the blood clotting mechanism, and its function as a biochemical amplifier. Nature (Lond.). 202:498-499.

2. Davie, E. W., and O. D. Ratnoff. 1964. Waterfall sequence for intrinsic blood clotting. Science (Wash. DC). 145:1310-1312.

3. Naito, K., and K. Fujikawa. 1991. Activation of human blood coagulation factor XI independent of factor XII. Factor XI is activated by thrombin and factor XIa in the presence of negatively charged surfaces. J. Biol. Chem. 266:7353-7358.

4. Gailani, D., and G. J. Broze, Jr. 1991. Factor XI activation in a revised model of blood coagulation. Science (Wash. DC). 253:909-912.

5. Josso, F., and O. Prou-Wartelle. 1965. Interaction of tissue factor and factor VII at the earliest phase of coagulation. Thromb. Diath. Haemorrh. 17:35-44.

6. Osterud, B., and S. I. Rapaport. 1977. Activation of factor IX by the reaction product of tissue factor and factor VII: additional pathway for initiating blood coagulation. Proc. Natl. Acad. Sci. USA. 74:5260-5264.

7. Bauer, K. A., B. L. Kass, H. ten Cate, J. J. Hawiger, and R. D. Rosenberg. 1990. Factor IX is activated in vivo by the tissue factor mechanism. Blood. 76:731-736.

8. Bauer, K. A., B. L. Kass, H. ten Cate, M. A. Bednarek, J. J. Hawiger, and R. D. Rosenberg. 1989. Detection of Factor X activation in humans. Blood. 74:2007-2015.

9. Bauer, K. A., P. M. Mannucci, A. Gringeri, F. Tradati, S. Barzegar, B. L. Kass, H. ten Cate, A. S. Kestin, D. B. Brettler, and R. D. Rosenberg. 1992. Factor IXa-factor VIIIa-cell surface complex does not contribute to the basal activation of the coagulation mechanism in vivo. Blood. 79:2039-2047.

10. Ruf, W., A. Rehemtulla, and T. S. Edgington. 1991. Phospholipid-independent and -dependent interactions required for tissue factor receptor and cofactor function. J. Biol. Chem. 266:2158-2166.

11. Hedner, U., and W. Kisiel. 1983. Use of human Factor VIIa in the treatment of two hemophilia A patients with high titer inhibitors. J. Clin. Invest. 71:1836-1841.

12. Hedner, U., S. Glazer, K. Pingel, K. A. Albert, M. Blomback, S. Schulman, and H. Johnson. 1988. Successful use of recombinant factor VIIa in a patient with severe hemophilia A during synovectomy. Lancet. ii:1193.

13. Macik, B. G., J. Hohneker, H. R. Roberts, and A. M. Griffin. 1989. Use of recombinant activated factor VII for treatment of a retropharyngeal hemorrhage in a hemophilic patient with a high titer inhibitor. Am. J. Hematol. 32:232-234.

14. Osterud, B. 1983. How to measure factor VII and factor VII activation. Haemostasis. 13:161-168.

15. Telgt, D. S., B. G. Macik, D. M. McCord, D. M. Monroe, and H. R. Roberts. 1989. Mechanism by which recombinant factor VIIa shortens the aPTT: activation of factor $\mathrm{X}$ in the absence of tissue factor. Thromb. Res. 56:603-609.

16. Rao, L. V. M., and S. I. Rapaport. 1990. Factor VIIa-catalyzed activation of factor $\mathrm{X}$ independent of tissue factor: its possible significance for control of hemophilic bleeding by infused factor VIla. Blood. 75:1069-1073.

17. Lau, H. K., J. S. Rosenberg, D. L. Beeler, and R. D. Rosenberg. 1979. The isolation and characterization of a specific antibody population directed against the prothrombin activation fragments $F_{2}$ and $F_{1+2}$. J. Biol. Chem. 254:87518761 .

18. Teitel, J. M., K. A. Bauer, H. K. Lau, and R. D. Rosenberg. 1982. Studies of the prothrombin activation pathway utilizing radioimmunoassays for the $F_{2} /$
$F_{1+2}$ fragment and the thrombin-antithrombin complex. Blood. 59:1086-1097.

19. Liebman, H. A., S. A. Limentani, B. C. Furie, and B. Furie. 1985. Immunoaffinity purification of factor IX (Christmas factor) by using conformationspecific antibodies directed against the factor IX-metal complex. Proc. Natl. Acad. Sci. USA. 82:3879-3883.

20. Laemmli, U. K. 1970. Cleavage of structural proteins during the assembly of the head of bacteriophage $\mathrm{T}_{4}$. Nature (Lond.). 227:680-685.

21. Greenwood, F. C., W. M. Hunter, and J. S. Glover. 1963. The preparation of ${ }^{131}$ I-labelled growth hormone of high specific radioactivity. Biochem. J. 89:114-123.

22. Nosslin, B. 1973. Analysis of disappearance time-curves after single injection of labelled proteins. CIBA Found. Symp. 9:113-130.

23. Thim, L., S. Bjoern, M. Christensen, E. M. Nicolaisen, T. Lund-Hansen, A. H. Pedersen, and U. Hedner. 1988. Amino acid sequence and posttranslational modifications of human factor VIla from plasma and transfected baby hamster kidney cells. Biochemistry. 27:7785-7793.

24. Morrissey, J. H., D. S. Fair, and T. S. Edgington. 1988. Monoclonal antibody analysis of purified and cell-associated tissue factor. Thromb. Res. 52:247-261.

25. Ruf, W., and T. S. Edgington. 1991. An anti-tissue factor monoclonal antibody which inhibits TF-VIIa complex is a potent anticoagulant in plasma. Thromb. Haemostas. 66:529-533.

26. Zar, J. H. 1974. Biostatistical Analysis. Prentice-Hall, Inc., Englewood Cliffs, NJ. 620 pp.

27. Radcliffe, R., and Y. Nemerson. 1975. The activation and control of factor VII by activated factor $\mathrm{X}$ and thrombin. Isolation and characterization of a single chain form of factor VII. J. Biol. Chem. 250:388-395.

28. Seligsohn, U., B. Osterud, S. F. Brown, J. H. Griffin, and S. I. Rapaport. 1979. Activation of human factor VII in plasma and in purified systems. Roles of activated Factor IX, kallikrein, and activated Factor XII. J. Clin. Invest. 64:1056-1065.

29. Nakagaki, T., D. C. Foster, K. L. Berkner, and W. Kisiel. 1991. Initiation of the extrinsic pathway of blood coagulation: evidence for the tissue factor dependent autoactivation of human coagulation factor VII. Biochemistry. 30:10819-10824.

30. Zur, M., R. D. Radcliffe, J. Oberdick, and Y. Nemerson. 1982. The dual role of factor VII in blood coagulation. Initiation and inhibition of a proteolytic system by a zymogen. J. Biol. Chem. 257:5623-5631.

31. Williams, E. B., S. Krishnaswamy, and K. G. Mann. 1989. Zymogen/enzyme discrimination using peptide chloromethyl ketones. J. Biol. Chem. 264:7536-7545.

32. Rapaport, S. I. 1991. The extrinsic pathway inhibitor: a regulator of tissue factor dependent blood coagulation. Thromb Haemostas. 66:6-13.

33. Novotny, W. F., M. Palmier, T. C. Wun, G. J. Broze, Jr., and J. P. Miletich. 1991. Purification and properties of heparin-releasable lipoprotein-associated coagulation inhibitor. Blood. 78:394-400.

34. Broze, G. J., Jr., and J. P. Miletich. 1987. Characterization of the inhibition of tissue factor in serum. Blood. 69:150-155.

35. Mann, K. G., M. E. Nesheim, W. R. Church, P. Haley, and S. Krishnaswamy. 1990. Surface-dependent reactions of the vitamin K-dependent enzyme complex. Blood. 76:1-16.

36. Fiore, M. M., P. F., Neuenschwander, and J. H. Morrissey. 1992. An unusual antibody that blocks tissue factor/factor VIIa function by inhibiting cleavage only of macromolecular substrates. Blood. 80:3127-3134.36.

37. Lawson, J. H., and K. G. Mann. 1991. Cooperative activation of human factor IX by the human extrinsic pathway of blood coagulation. J. Biol. Chem. 266:11317-11327.

38. Wilcox, J. N., K. M. Smith, S. M. Schwartz, and D. Gordon. 1989. Localization of tissue factor in the normal vessel wall and in the atherosclerotic plaque. Proc. Natl. Acad. Sci. USA. 86:2839-2843.

39. Drake, T. A., J. H. Morrissey, and T. S. Edgington. 1989. Selective cellular expression of tissue factor in human tissues. Implications for disorders of hemostasis and thrombosis. Am. J. Pathol. 134:1087-1097.

40. Wissler, R. W., and D. Vesselinovitch. 1977. Atherosclerosis in nonhuman primates. Adv. Vet. Sci. Comp. Med. 21:351-420.

41. Moore, K. L., S. P. Andreoli, N. L. Esmon, C. T. Esmon, and N. U. Bang. 1987. Endotoxin enhances tissue factor and suppresses thrombomodulin expression of human vascular endothelium in vitro. J. Clin. Invest. 79:124-130.

42. Conway, E. M., R. Bach, R. D. Rosenberg, and W. H. Konigsberg. 1989. Tumor necrosis factor enhances expression of tissue factor mRNA in endothelial cells. Thromb. Res. 53:231-241.

43. Dvorak, H. F., D. R. Senger, A. M. Dvorak, V. S. Harvey, and J. McDonagh. 1985. Regulation of extravascular coagulation by microvascular permeability. Science (Wash. DC). 227:1059-1061.

44. Weiss, H. J., V. T. Turitto, H. R. Baumgartner, Y. Nemerson, and T. Hoffmann. 1989. Evidence for the presence of tissue factor activity on subendothelium. Blood. 73:968-975.

45. Bauer, K. A., L. M. Weiss, D. Sparrow, P. S. Vokonas, and R. D. Rosenberg. 1987. Aging-associated changes in indices of thrombin generation and protein $\mathrm{C}$ activation in humans. Normative aging study. J. Clin. Invest. 80:15271534. 